\title{
Kriminaliteten og mediene
}

\author{
Af Sigurd Allern ${ }^{1}$
}

\begin{abstract}
The news media's justification for the priority given to crime stories is usually formulated as representing a societal task and duty: police, prosecutors and the judicial branch of government must be scrutinized for the good of democracy. However, independent, critical investigations are rare in this area of journalism. The explanation for this may reflect the resources, time and legal knowledge that carefully-crafted crime journalism requires. Market-oriented values give other priorities. Journalists, like police investigators, often work under great time pressure; quick »results" are demanded. The media's reliance on police sources is also high. In cases where both parties seem to have 'tunnel vision' concerning the case and its suspects, the media can - as several criminal cases in Scandinavia have shown - contribute to a miscarriage of justice."
\end{abstract}

Journalisters begrunnelse for kriminalstoffet formuleres gjerne offensivt: politi, påtalemyndigheter og den dømmende statsmakt må granskes til beste for demokratiet. Akkurat som journalister engang kjempet seg til retten å rapportere fra parlamentsdebatter, noe som er opprinnelsen til begrepet »den fjerde statsmakt «, har mediene erobret retten til å rapportere relativt fritt om politietterforskning, tiltale, siktelser, rettssaker og domsbeslutninger.

Bjugn-saken i Norge på 90-tallet ${ }^{2}$ blir svært ofte trukket fram av norsk presse som et eksempel på at god journalistikk kan bidra til å hindre en større rettsskandale (Bodahl-Johansen \& Østbye 1996, Kringstad 1997). Og eksemplet er godt, men enkelte journalisters kritiske innsats i Bjugn-saken er dessverre lite typisk for kriminaljournalistikken. Rettsskandaler i mange land viser at feil person både kan bli mistenkt, tiltalt og dømt uten at nyhetsmediene representerer noen spesiell motkraft. Privatetterforskeren Tore Sandbergs avsløringer i drapssakene som Per Liland $^{3}$ og Fritz Moen ${ }^{4}$ ble dømt og til slutt frikjent for, viser utvilsomt betydningen av journalistiske metoder når justismord skal avdekkes. Men det var etter at journalisten Sandberg sluttet i NRK at han utviklet og demonstrerte sine egen-

* Title in English: Crime and the media. 
skaper som en uavhengig etterforsker i kriminalsaker. Ofte gir etablerte medier gir gjennom sitt tette samarbeid med politiet og sin avhengighet av offisielle kilder, heller et aktivt eller passivt bidrag til at retten i noen tilfeller dømmer på et utilstrekkelig eller feilaktig grunnlag.

Årsaken er slike saker kan for eksempel være vitneutsagn som senere viser seg ikke å holde mål - eller i enkelte tilfeller at det foreligger falske tilståelser. Den erfarne politietterforskeren Asbjørn Rachlew (2009) har i en avhandling i kriminologi belyst noen av de mekanismene i politiarbeidet som kan føre til selektiv etterforskning slik at politiet går i en »bekreftelsesfelle«. Ask og Granhag (2008: 163-165) påpeker i en svensk lærebok i Rättspsykologi at en slik seleksjon fører til at det hypotetiske narrativet - altså om en bestemt mistenkt persons skyld - i for stor grad får styre etterforskningen. Det som peker i en annen retning overses. Selektivitet og tunnelsyn er imidlertid også et problem i journalistikken. Journalister jobber i likhet med politietterforskere ofte under hardt tidspress, med krav om raske »resultater «. Når politietterforskere og sentrale journalister har tette relasjoner kan resultatet fra et rettssikkerhetssynspunkt bli katastrofalt. To parter i samme tunnel ser ikke bedre enn én.

En nylig avsluttet svensk rettskatastrofe er et skrekkeksempel på dette. I august 2013 ble den siste dommen mot den psykiatriske pasienten Sture Bergwall, kjent under navnet Thomas Quick, opphevet. Han var tidligere dømt skyldig i å ha myrdet åtte personer. Tre av disse dommene gjaldt mord han selv hevdet å ha begått i Norge. Dagbladet-redaktøren John Olav Egeland fulgte opp avgjørelsen med kommentaren »De skapte en massemorder« (Dagbladet.no 31.7 2013). Også de norske justismyndighetene rolle i Quick-saken må granskes, krever han. Forhåpentligvis vil det også skje når Norge, ifølge justisministeren Grete Faremo, nå skal medvirke i den svenske evalueringen av påtalemyndighetenes og rettspsykiatriens rolle i Quick-saken.

Dessverre glemte redaktøren å nevne at det også er et behov for å granske medienes rolle i denne rettsskandalen. For det var jo gjennom et langvarig samspill mellom journalister, politi og psykiatrisk ekspertise at Bergwall gjennom et tiår ble mediert som seriemorder; et gruoppvekkende nordisk svar på roman- og filmfiguren »Hannibal Lechter«.

Allerede etter de første år med påstander og tilståelser fra pasienten på Säter, skrev Georg Apenes en syrlig kommentar (Dagens Næringsliv 1.6 1996) om Quick som medieføljetong:

Han representerer alt hva en noe over middels ambisiøs nyhetsredaktør kan ønske seg: En sinnslidende, antatt massemorder omgitt av et politikorps og klinisk fordomsfrie psykoterapeuter 
som det er lett å få kontakt med og som villig forteller siste nytt om Thomas. Dette inngår muligens som ledd i behandlingen. Selv er han den høflige, velartikulerte og fremfor alt angrende klient som mer enn gjerne lar seg intervjue av norsk radio og norske aviser. Han er jo helt vanlig; det kunne like godt ha vært deg eller meg. Men det er det altså ikke - å herlige gru! Slamsugingen etter corpus delicti gjør seg derimot best på TV.

Ja, så interessant var Bergwall blitt i rollen som Thomas Quick at Dagbladet og radiokanalen P4 i mai 1996 brøt alle normale kildeprinsipper og utbetalte honorar for å få eksklusive intervjuer med den selverklærte seriemorderen $i$ hans rom på Säter psykiatriske klinikk. ${ }^{5}$ Ifølge Journalisten.no (24.9.2012) betalte Dagbladet for intervjuet med å gi han en PC. ${ }^{6}$ I tillegg fikk han tilsendt avisklipp om seg selv og de sakene han var involvert i.

Både norske og svenske redaktører vil, forståelig nok, gjerne sole seg litt i glansen av at det til sjuende og sist var en journalist, Hannes Råstam, som bidro til at Bergwall trakk de falske tilståelsene tilbake. Og gjennom tre dokumentarer i SVT og en etterfølgende bok, utgitt like etter at forfatteren selv døde av kreft, har Råstam (2012) vist sprengkraften i god, undersøkende journalistikk. Det var også noen få andre journalister som opp gjennom årene påviste svakheter i etterforskningen og diskuterte det urimelige i tilståelsene, blant dem Johan Håkansson i avisen Norrlänska Socialdemokraten i Luleå og Jan Guillou. Men de var unntak fra hovedstrømmen, akkurat som noen få fagfolk innen rettspsykiatri, vitnepsykologi og politietterforskning var det innen sine profesjoner. I 1995 påstod for eksempel Bergwall i rollen som Quick at han hadde drept og begravd to unge gutter som tidligere var meldt forsvunnet fra et asylmottak i Norge. Nyheten fikk store oppslag, men viste seg raskt å være en bløff - de levde begge i beste velgående $\mathrm{i}$ Sverige og Kanada. Heller ikke det rokket ved hans seriemorderimage i mediene. I 1996 deltok både presse og kringkasting med liv og lyst i å dramatisere jakten på likrester i jord og sølevann i indre Østfold. Da Bergwall/Quick ble tiltalt for drap på Therese Johannesen i 1998, rekonstruerte VG rekonstruksjonen året før under overskriften »Tror på Quick« og fortsatte:

Han stopper brått. Setter seg på huk ved den lille bjerken. Thomas Quick blir sittende i stillhet en lang stund. Nøyaktig her var det han begravde den lille Therese Johannessen sommeren 1988.

Avisen legger til at Therese-etterforskerne har funnet beinrester etter et menneske der Quick forklarte at ugjerningen fant sted. Det viste seg senere å være en brent trebit. I en omtale av Råstams bok (VG 13.8.2012) oppsummerer tidligere VGredaktør Bernt Olufsen at både etterforskning og journalistikk drives fremover av 
ønsket om oppklaring. Han nevner som eksempel at ved ett tilfelle ville to av hans reportere starte graving etter Therese Johannessen i et sandtak for egen hånd. Denne varianten av gravende journalistikk ble heldigvis stanset av avisledelsen. Og han legger selvkritisk til:

Kjølig analytisk distanse er sjeldnere til stede. Jeg kjenner journalister som har dekket både etterforskningen og rettssaken mot Per Liland og som dekket de to drapene Fritz Moen ble dømt for. Flere av dem lot seg ikke, for å si det forsiktig, imponere av Tore Sandbergs avsløring av justismord og dobbelt justismord. Kanskje trakk vi for hastige konklusjoner i Quick-saken, også ...

»Kanskje« er neppe ordet.

Nyheter om kriminalitet og rettssaker har helt siden den trykte pressens barndom representert en prioritert del av nyhetsmedienes redaksjonelle innhold. Fra et kildekritisk perspektiv har kvaliteten vært sterkt vekslende. Det er imidlertid ikke tvil om at løssalgspressen - the populars - på godt og ondt har vært drivende i å sette kriminalitet som samfunnsfenomen på dagsordenen (Pollack 2001, 2008). En innholdsanalyse jeg gjorde av ti norske aviser like før årtusenskiftet (Allern 2001), viste at denne typen nyhetsstoff en fast og høyt prioritert ingrediens i VGs stoffmiks, mens aviser som Vårt Land og Dagens Næringsliv vanligvis ikke omtaler drap, ran og voldtekt. De undersøkte region- og lokalavisene ligger på et mellomnivå. Studier av norske fjernsynsnyheter viser at det reklamefinansierte TV2 etter etableringen tidlig i 1990-årene raskt gjorde krimnyheter til en fast del av nyhetsstoffet, noe et nølende NRK etter hvert kopierte (Sand \& Helland 1998, Waldahl \& al 2002, 2009). Senere har utallige nettmedier, som ofte kopierer populærpressens stoffprofil i jakten på oppmerksomhet, bidratt til å gjøre kjapt produsert nyhetsstoff om kriminalitet til en nærmest døgnkontinuerlig virksomhet.

Det mer forretningsmessige motivet for kriminaljournalistikken uttrykkes sjelden direkte av mediefolk, men er i praksis minst like tungveiende som de mer ideelle: rapporter om grov kriminalitet og oppsiktsvekkende rettssaker har stor publikumsinteresse. Krimstoff selger løssalgsaviser, høyner ratingen for tvnyheter og fører til ekstra klikk på nettet. Kravet til stoff som publikumsinteresse sørger for reklameinntjening er dessuten, i de børsnoterte medieselskapers tidsalder, blitt skjerpet.

Sjangermessig er krimstoffet mer ensidig enn mange andre stoffområder: nyhetsstoffet dominerer, featurestoff og kommentarer er mer sjeldne. Et featureunntak er Dagbladet Magasinet (3.11. 2012), som med tekst av en kjent forfatter og vennlige bilder har gjort det klart for offentligheten at en av de dømte søstrene i Orderudsaken, Veronica, i alle fall er hundens beste venn. 
Kriminaljournalistikken har - kanskje nettopp på grunn av dette innebygde spennet mellom butikk og etikk - spilt en svært viktig rolle i utviklingen av den journalistiske profesjonsetikken. Det ligger så og si i kriminaljournalistikkens »natur« at den går tett inn på enkeltmenneskers personlige liv. Det skjer gjennom rapporter om overgrep, ofre, mulige skyldige og samfunnets reaksjoner på lovbruddene. I jakten på et bredt publikum, leder dette lett til dramatiserende rapporter. Ønsket om personifisering betyr et vedvarende press for identifikasjon, navnepublisering og bilde. Samtidig er det et faktum at pressedekningen om kriminalitet i riktig gamle dager, før 2. verdenskrig, var langt råere, mer nærgående og detaljrik enn den stort sett er i dag. Forholdet mellom personvern, pressens egeninteresser og allmennhetens behov for å vite påvirkes både av tidsbestemte konvensjoner, lovgivning og hva publikum til enhver tid finner akseptabelt.

Det nordiske pressetiske systemet bygger i hovedsak på selvregulering og Johs Andenæs (1984: 457) oppsummerte i et foredrag for noen tiår siden at »Ønsket om å unngå inngrep fra lovgivningen har vært en vesentlig drivkraft ved etableringen av pressens selvjustis«. Hvordan selvjustisen utformes og praktiseres påvirkes hele tiden av endringer i samfunnet. De stadige revisjonene av den relativt detaljerte norske Var Varsom-plakaten er et eksempel på det. Et eksempel er omtale av selvdrap der det etter årtusenskiftet ble åpnet for friere adgang til publisering.

I skandinaviske land er det dessuten ulike tradisjoner og oppfatninger blant journalistene selv om hvor enkelte pressetiske grenser skal trekkes. Under Nordiske mediedager i Bergen våren 2013 ble det lagt fram en undersøkelse som viser at norske journalister i kriminalsaker er mer positive til navnepublisering før dom er falt enn sine svenske og danske kolleger. ${ }^{7}$ En ekstra grunn til et slike tradisjonelle presseetiske regler ser ut til å være på vikende front, er den muligheten nettsider, blogger og såkalt »sosiale« medier har gitt til publisering helt uavhengig av alle etiske regler og selvjustisorganer. I den kommersielle konkurransen vil alltid andres publisering bli brukt som et argument for å tøye grensene.

Journalistikk er kalt historiens kladdebok, men bør aldri kalles dens speil. Det er for eksempel ikke noe direkte og proporsjonalt forhold mellom kriminalstatistikken, f. eks om anmeldte lovbrudd, siktede personer eller straffereaksjoner, og medienes nyhetsdekning av kriminalitet (Pollack 2008). Nyhetsredaksjoner velger hele tiden temaer, kilder og vinkel, journalister fokuseres på noe og utelater annet. Dramatiske og spektakulære forbrytelser som terrorattentater, mord, drap, grove ran og narkotikasmugling har vanligvis forrang. Seksualiserte forbrytelser får ofte stor oppmerksomhet, spesielt hvis offeret er et barn eller en ung kvinne. I Knutby-saken i Sverige kunne sex og sekt, mord og drapsforsøk kombineres $i$ en eksplosiv mediecocktail med såpeoperaens ingredienser. 
Om kriminalstatistikken viser en økning eller minskning av visse typer forbrytelser betyr derfor lite eller ingenting for beskrivelsen av trusselbildene (Pollack 2008). Populærjournalistikkens utvalgte kriminalstoff gir derfor et heller spesielt bilde av kriminalitetsutviklingen i samfunnet. Det har også kriminalpolitiske ringvirkninger. Når oppslag om vold og ran florerer er høyrepopulismens rop om strengere straff, mer penger og flere uniformer ofte et vinnende konsept. Et typisk eksempel på denne typen medieregi er TV2s »folkemøte« om kriminalpolitikk foran stortingsvalget i 2009 i Norge. I panelet satt bl.a. daværende justisminister Knut Storberget (Ap) og Per Sandberg (FrP). I tillegg var flere ofre for kriminalitet med. Det siste var ingen tilfeldighet. Offerperspektivet har siden fra 1990årene blitt stadig mer sentralt i kriminaljournalistikken (Lindgren \& Lundström 2010, Pollack 2008). Programleder Oddvar Stenstrøm etablerte, som han hadde for vane, en svært tydelig tolkningsramme for diskusjonen: ${ }^{8}$

Ja, god kveld. Utenlandske forbryterbander herjer over hele landet. De tømmer boliger for verdisaker midt på lyse dagen, rundstjeler deg mens du sover i din egen seng, tømmer både bankkontoen og lommene dine for penger og viser en frekkhet uten sidestykke. Og nesten alle av dem slipper unna. Justisminister Knut Storberget, når så få blir tatt, betyr det at politiet egentlig er maktesløse i kampen mot disse bandene?

Det siste måtte selvsagt justisministeren svare nei til. FrPs Per Sandbergs erklærte da at han ville kalle en »spade for en spade«. Spaden bestod i vende programlederens ord om utenlandske forbryterbander på tjuveriturné til et spørsmål om »overfallsvoldtekter« som begås »av ikke-vestlige innvandrere« og unge innvandrere som »er overrepresentert på alle våre kriminalstatistikker«. Programlederen bedyret at det ikke var han som hadde gjort dette til en debatt om innvandrings- og asylpolitikk. Nei, han la bare ballen til rette for den nordiske høyrepopulismens standardnummer.

Senere i debatten regisserte TV2 inn innslag med ofre for kriminalitet, bl.a. en 91 år gammel dame som ble slått ned og ranet i sitt eget hjem. Etterforskningen viste at dette var en kriminell som tidligere hadde ranet flere kvinner, tallet 17 kriminelle forhold ble nevnt, og likevel, ifølge programlederen, hadde han »sluppet ut etter halv soning«. Justisminister Storberget kontret med at dette i tilfelle er i strid med alle regler for soning når det gjelder denne typen forbrytelser.

Litt senere kunne sønnen til den 91-årige kvinnen (Morten Eitveit) opplyse at det tross alt hadde kommet et lite lyspunkt etter tragedien:

Sønnen: Ja, Siv Jensen kom på besøk til mor. Rett etter overfallet. Frivillig. Altså, det var ingen ... Det var med TV2 da. 
Oddvar Stenstrøm: Det var valgkamp da.

Sønnen: Ja, det var det. Det var det det ble snakk om der. Siv sa ganske klart ... jeg sier Siv, altså ... det er klart.

Oddvar Stenstrøm: Ja

Sønnen: Men hun sa klart fra at vedkommende burde ha en dom som gikk på den første ... når han slo ned, og neste så skulle det legges på og videre oppover ...

$\AA$ diskutere kriminalpolitikk i en setting dominert av FrP-leder Siv Jensen på hjemmebesøk i valgkampen - assistert av TV2 - det er i sannhet ingen enkel oppgave.

Kriminaljournalisters arbeid knyttes ofte til et fenomen Riksadvokaten og statsadvokatene liker spesielt dårlig: Lekkasjer av taushetsbelagt informasjon. Begrunnelse er at dette kan ødelegge for etterforskningen og svekke tilliten til rettsapparatet. De kan også, som lekkasjene av de psykiatriske rapportene under 22. juli-rettsaken viste, potensielt påvirke rettsprosessen.

Ordet lekkasje kan imidlertid lett gi litt feil assosiasjoner. Et vannrør som springer lekk er vanligvis uønsket av alle som rammes. En lekkasje til medier er alltid villet og planlagt. Den som lekker representerer normalt en interesse som mener seg å tjene på lekkasjen, selv om det også finnes lekkasjer med mer altruistiske motiver. Lekkasjer fra forsvarsadvokater i kriminalsaker skjer vanligvis til beste for egen klient. Lekkasjene kan sånn sett fungere som en offentlig sikkerhetsventil og sikre at andre virkelighetsbilder enn de som politiet filtrerer kommer fram. Spesielt gjelder det saker der den offisielle informasjonen oppfattes som ensidig. Garvete journalister vet dessuten at også enkelte i politiet »lekker« informasjon som etterforskningsledelsen ikke vil eller kan bekrefte offentlig - men som noen gjerne vil ha ut likevel.

Det er samtidig verd å huske, spesielt for journalister som elsker åpenhet, at i lekkasjer er det normalt kilden som har initiativet og bestemmer premissene. En redaksjon som ikke kritisk vurderer kildens motiver for å lekke og tar stilling til »timingen«, bryter med elementære prinsipper for kildekritikk. Når kilden dessuten insisterer på anonymitet øker risikoen for feilinformasjon når det ikke finnes alternative kilder. At et vitne har sagt noe i et avhør som lekkes kan være korrekt referert, men det er ingen garanti for at informasjonen er sann. Som internasjonal forskning om vitneutsagn har kartlagt er falske minner mer utbredt enn de fleste av oss tror. Vitner kan dessuten påvirke hverandre hvis de kommuniserer før avhør tas, noe som skjedde etter at utenriksminister Anne Lindh ble hugget ned med kniv på et varehus i Stockholm (Ask, Granhag \& Christiansson 2008: 349). Like etter ble en 35-årig mann arrestert som »skäligen mistenkt«. Noen dager sene ble 
han sluppet fri. Men i mellomtiden var han i praksis identifisert av en rekke medier. Rask og ukritisk publisering kan ikke bare skade en etterforskning - den kan også villede opinionen og svekke tilliten til rettsprosessen.

Lekkasjer er nøye knyttet til at journalistenes viktigste kilder i kriminalsaker er politiet og forsvarsadvokatene (Høst \& Bodahl Johansen 2001). I store saker inngår til og med mediekontakt i advokaters salærkrav. Kontakten kan være svært tett, og handler ikke bare om informasjonsutveksling til gjensidig nytte, den er også uttrykk for en strategisk kilde- og mediepleie. Nærheten gjelder tydeligvis påtalemyndigheten, som selv om den holder seg unna alt som smaker av lekkasjer, ønsker et best mulig forhold til mediemakten. Etter at Orderud-saken var avsluttet aksepterte for eksempel to statsadvokater å bli påspandert middag på topprestauranter av både Dagbladet og VG (Brurås og Røssland, 2003). Alle parter ser i dagens medieklima dette som strategisk »relasjonsbygging «. You scratch my back - I'll scratch yours. Problemet er at det i lengden skaper en nærhet som spesielt for pressen kan bli problematisk. I forhold til nyhetsmediene har det norske politiet som samfunnsinstitusjon - i det minste opp til tiden etter 22. juli 2011 levd et relativt beskyttet liv - og sjelden blitt utsatt for et systemkritisk, journalistisk blikk.

La meg derfor helt til slutt, ganske kort, si noe om medienes rolle i denne dekningen av terroraksjonen. Omfanget av mediedekningen ble og måtte nødvendigvis bli massivt, nasjonalt som internasjonalt. Tiden tillater bare å berøre noen få aspekter av denne rapporteringen. Vi kan her - som Brurås (2012) har gjort i en analyse - skille mellom tre distinkte faser fram til selve rettssaken ble hovedsaken. Den første var de første kaotiske timene og dagene med dramatisk nyhetsrapportering. Deretter fulgte neste fase der konsekvensene av terroraksjonen ble en klassisk mediebegivenhet, dominert av minnestunder, begravelser og andre sorgritualer. Her spilte de fleste medier med sordin. Etter disse ukene kom en tredje fase, med gradvis normalisering av dekningen, inkludert med rom for mer pågående spørsmål om beredskap, politiinnsats, svikt og politiske ansvarsforhold

Et viktig utgangspunkt når vi bedømmer dekningen i den første fasen er at politisk terrorisme alltid har et propagandistisk mål, ønsket er maksimal mediedekning med en regi som passer terrorismens mål. Breivik planla denne propagandadelen like nøye som logistikken, bomben og væpningen. Dels gjorde han det ved å utnytte internett til å distribuere sitt »Manifest«, og få medieomtale av dette, men han gjorde det også ved å legge ut arrangerte bilder av seg selv som »soldat« og »frimurer « som PR-subsidier til pressen. Dessverre slukte flere redaksjoner dette agnet med søkke og snøre. Først etter motreaksjoner og kritikk forsvant Breiviks egne propagandabilder fra forsidene. 
Et annet interessant trekk ved mediedekningen i de aller første timene er at bombingen og massakren naturlig nok ble definert som terrorisme av alle redaksjoner - og i noen nettmedier og tv-kanaler også knyttet til spekulasjoner om muslimer og Al Qaida. I innholdsanalyser av NRK og Dagsavisen er det kartlagt en interessant vending i språkbruken i timene etter at Breiviks identitet ble kjent: da det viste seg at drapsmannen og propagandisten ikke var muslim, men en kristen høyreekstremist fra Oslo vest, ble også bruken av betegnelsen terror om bomben mot regjeringskvartalet og massakren på Utøya sterkt nedtonet (Grydeland 2012). En mulig og sannsynlig årsak kan være at hans bakgrunn i sterk grad brøt med de tolkningsrammene knyttet til terroraksjoner som på forhånd var etablert. Terrorister er bokstavlig talt »de andre«. Senere endret det seg.

Mye rosende er sagt om norske mediers seriøse og empatiske opptreden i den rituelle sorgfasen som deretter fulgte. Klagene til Pressens faglige utvalg har da også, gitt dekningens omfang, vært få. Like naturlig var det at rapportene om minnehøytideligheter, begravelser og sorg ble etterfulgt av periode med mer pågående og kritiske spørsmål. Hvor pågående og analytisk den i realiteten ble er et annet spørsmål. I alle fall er det interessant å konstatere at den virkelige skarpe gjennomlysningen og sammenfatningen av det som skjedde, av svikt og institusjonelle ansvarsforhold, først kom da en regjeringsoppnevnt, selvstendig granskningskommisjon la fram sin rapport. Kommisjonen hadde utvilsomt en direkte adgang til nøkkelkilder med vitneansvar som journalister ikke nyter godt av. Men som den tidligere sjefredaktøren Kåre Valebrokk uttalte til VG (8. august 2012): »Det måtte en jurist og et utvalg til for å sette ansvaret på plass. Hva ventet pressen på?«

Redaktører blåser ofte i basunene om behovet for en uavhengig kritisk journalistisk granskning på de fleste områder, men vi ser det sjelden når det gjelder arbeidet til politi, påtalemyndigheter og domstoler. En årsak kan være at det krever både ressurser og juridisk kompetanse. Men noen ganger er prioriteringen høy. Det var som kjent ikke antallet journalister og spalteplassen som ble satt av for å dekke den selverklærte seriemorderen Thomas Quick det var noe i veien med. Problemet var at de fleste tenkte på den samme måten som sine politi- og ekspertkilder - og at dramaturgien de i fellesskap skapte passet som hånd i hanske både for en påtalemakt på villspor og for kommersialiserte medier på publikumsjakt. 


\section{Noter}

1. Professor, dr.polit. Sigurd Allern arbejder ved Institutt for medier og kommunikasjon, Universitetet i Oslo.

2. Saken gjaldt omfattende etterforskning om påståtte seksuelle overgrep mot barn i Bjugn kommune i Sør-Trøndelag i 1996. Flere titalls personer ble omfattet av etterforskningen. Én ble tiltalt, men frikjent av Frostatings lagmannsrett.

3. Per Kristian Liland ble i 1970 dømt til 21 års fengsel og ti års sikring for mord på to personer i Fredrikstad i 1969. Han hevdet hele tiden at han var uskyldig. Flere personer engasjerte seg i kritikken av dommen, blant dem var Tore Sandberg, som etter egen etterforskning ga ut en kritisk bok om saken (Sandberg 1992). Nye rettsmedisinske bevis og vitneforklaringer førte til at saken ble gjenopptatt, og Liland ble til slutt frikjent av Eidsivating lagmannsrett i 1994. Året etter ble han tilkjent 13,7 millioner kroner i oppreisning og erstatning.

4. Fritz Moen, som var døvstum, ble i 1978 dømt for å ha voldtatt og drept en ung kvinne i Trondheimsområdet. I 1981 ble han i tillegg dømt for i 1976 å ha tatt livet av en annen kvinne. Tore Sandberg engasjerte seg fra 1998 og utover sterkt i begge disse saken og hevdet at det var begått et justismord. I 2004 ble Moen frikjent for det ene drapet, og etter at en mann på dødsleiet hadde tatt på seg skylden for begge drapene, ble han i 2006 også frikjent for det andre. Moen døde året før den siste avgjørelsen. Sandberg ga ut en bok om Moen-sakene i 2008.

5. Intervjuet ble trykt i Dagbladet 25. mai 1996.

6. Kilde: Journalisten.no 24.9.2012.

7. http://nordiskemediedager.no/nyheter/skandinaviske-journalister-uenige-om-medieetikk/

8. Programmet er omtalt i Allern (2011).

\section{Referanser}

Allern, S. (2001). Nyhetsverdier. Om markedsorientering og journalistikk i ti norske aviser. Kristiansand: IJ-forlaget.

Allern, S. (2011). Fjernsynsvalgkampen. Program, deltakere og maktkamp 1961-2009. Oslo: Pax forlag

Andenæs, J. (1984) Rettsvesenet og massemedia. Foredrag holdt på det 30. nordiske juristmøtet. Oslo 15.-17. august: http://jura.ku.dk/njm/30/30_19.pdf/

Ask, K. \& Granhag, P.A. (2008) Psykologiska påverkansfaktorer vid utredningsarbete. I Granhag, P.A. \& Christianson, Å. (red.) Handbok i rättspsykologi. Stockholm: Liber.

Ask, K., Granhag, P.A. \& Christianson, S.A. (2008). Falska minnen och falska erkännanden. I Granhag, P.A. \& Christianson, S.Å. (red.) Handbok i rättspsykologi. Stockholm: Liber.

Bodahl-Johansen, G. \& Østbye, H. (1996). Pressen og Bjugn-saken. Fredrikstad: Institutt for Journalistikk.

Brurås, S. \& Røssland, L.A. (2003). Kompiser i krim: aktører, strategier og relasjoner i mediedekningen av Orderud-saken. Oslo: Norsk Journalistlag.

Brurås, S, red. (2012). Mediene og terroraksjonen: Studier av norske mediers dekning av 22. juli. Oslo: Unipub

Granhag, P.A. \& Christianson, S.Å. (red.). Handbok i rättspsykologi. Stockholm: Liber.

Grydeland, K. (2012). »Fra »terror« til »tragedie«. Medienes förste tolkninger av terroraksjonen«. I Brurås, S, red. (2012). Mediene og terroraksjonen: Studier av norske mediers dekning av 22. juli. Oslo: Unipub 
Høst, S. \& Bodahl-Johansen, G. (2001). Kulturforskjell og tilpasning: journalisters forhold til politi, påtalemyndighet og domstoler. Fredrikstad: Institutt for Journalistikk.

Kringstad, H. (1997). Bjugn-formelen. Oslo: Tiden forlag.

Lindgren, S. \& Lundström, R. (2010). Ideala offer, och andra: Konstruktionen av brottsdrabbade i media. Malmö: Gleerups.

Pollack, E. (2001). En studie i medier och brott. Fil. dir. avhandling v Institutionen för journalistik, medier och kommunikation, Stockholms universitet.

Pollack, E. (2008). Medier och brott. I Granhag, P. \& Christiansson, S.Å. (red.) Handbok i rättspsykologi. Stockholm: Liber.

Rachlew, A. (2009). Justisfeil ved politiets etterforskning - noen eksempler og forskningsbaserte mottiltak. PhD-avhandling ved Det juridiske fakultet, Universitetet i Oslo.

Røssland, L.A. \& Brurås, S. (2003)

Råstam, H. (2012). Fallet Thomas Quick. Att skapa en seriemördare. Stockholm: Ordfront.

Sand \& Helland (1998). Bak TV-nyhetene. Produksjon og presentasjon i NRK og TV2. Bergen: Fagbokforlaget.

Sandberg, T. (1992). Øksedrapene i Lille Helvete. Oslo: Scanbok.

Sandberg, T. (2008). Overgrepet - Justismordene på Fritz Moen. Oslo: Damm.

Waldahl, R., Andersen M.B. \& Rønning, H (2002) Nyheter først og fresmst. Norske tv-nyheter: Myter og realiteter. Oslo: Universitetsforlaget.

Waldahl, R., Andersen, M.B. \& Rønning, H. \& (2009). Tv-nyhetenes verden. Oslo: Universitetsforlaget. 